\title{
The Practice and Research of Orff's Music Teaching Method in Contemporary Chinese Music Teaching
}

\author{
Guo Wei \\ College of Arts, Xiamen university, Xiamen, China,361000
}

\begin{abstract}
Keywords: Orff music teaching method, application localization, Chinese music teaching,current problems in Chinese music class , foreign cultures
\end{abstract}

\begin{abstract}
As the greatest music research method in the world, Orff's music teaching method is praised by many countries in their own music education. But in the process of advocating and developing, it is more important to pay more attention to the combination of Orff music teaching method with the national conditions, history and culture, without abandon the traditional ideas and music education concepts inherent in the country. Chinese culture is even more profound. It has a very normal rejection mentality for foreign cultures. Therefore, under the premise of retaining the essence of the original Chinese music education culture, we should learn from and draw on the advantages of the Orff music teaching method. This article analyzed the theory localization and application localization of Orff's music teaching method in Chinese music teaching, and the problems and countermeasures for the current problems in Chinese music class, and analyzed ways and cases to combine Orff music teaching method with Chinese music teaching theory.
\end{abstract}

\section{INTRODUCTION}

Orff's music teaching method is a new music teaching method that is different from the traditional music teaching theory and method. It has produced a profound and extensive influence on various countries and regions in the world. In the process of constructing his original and elemental theory of music education, Orff profoundly realized that music culture should not only be centered on a certain musical culture in the world, but should absorb the advantages of various advanced cultures.Combine the local national conditions to carry on the diversified development.Orff's music teaching method advocates the use of ingenious methods of emotional resonance, emotional experience and emotional stimulation to communicate with students in the heart and mind. Music education in China tends to focus only on the singing of songs and the mechanical memory of lyric tunes, which did not cultivate students' music appreciation. Therefore, Chinese students generally lack initiative, personality and creativity in music learning, and have not achieved the proper level of music appreciation. In the promotion of music teaching methods in China, it should take the national situation and students' existing music appreciation standards into consideration, to fully draw lessons from the advantages of Orff's music teaching method and work out a music teaching method suitable for Chinese students. The process of indigenization of educational theory is, to a large extent, a cross-cultural communication process. The development of any kind of culture requires the use of its own mother and the soil suitable for its growth as a "gene". The exchanges between exotic and heterogeneous cultures can only take root in the motherland and soil of the local culture to find roots, bloom, and fruit. Finally, they are accepted and merged into new nutrients and organic components of local culture. That is to say, the exchange and combination of exotic and heterogeneous cultures is not an act of copying, but a choice; it is not a superposition but a reconstruction; it is not welding, but melting; it is not transformation but innovation. Orff's concept of music education, combined with its own cultural characteristics, continues to create new teaching modes in the music teaching practice of different countries, nations, and regions. This is Orff's localized music education concept.

The study of Orff's music teaching method in contemporary Chinese music teaching should include the characteristics of the country's culture in terms of theoretical methods, practical operations, etc., rather than the "whole Westernization" without thinking. For example, as some Western scholars have pointed out, "The power of the Internet is ultimately manifested in the fact that 
it makes the entire world think and write like North Americans." This copy of the West must be irreconcilable to the integration of Chinese and Western cultures.

\section{ORFF MUSIC TEACHING METHOD FEATURES}

The most significant feature of Orff's music teaching method is to pay attention to the development of the inner world of the students. It requires that the students do not regard music as a burden or utility, but devote themselves to the music world with their body, language and musical instruments, and express their inner world in a unique way. When music becomes a child's own needs, students are naturally relaxed, fast, and ingrained in mastery of music, music, performance, performance and language culture. At the same time, Orff music teaching method emphasizes the creation of creative spirit. In class, students use fish frog to imitate frog sound, use wind bell to describe the spring river fine wind, play sticks and beat limbs to deduce rhythm, a pleasant and moving symphony is born among the students. Orff music provides infinite space for students to develop their individuality, and also gives students collective consciousness and cooperation spirit in collective performance.

Orff's music teaching method follows the requirements of music education, takes social needs as a benchmark, and practical teaching as the main line. It fully utilizes and uses the coordination of the body, language, and musical instruments in the Orff music teaching method, focusing on cultivating students' development of the inner world. Learning and understanding music professional knowledge by means of play, performance, rhythm, storytelling, and so on. This way is to learn and strengthen the other kinds of intelligence by sensory stimulation, rather than to learn music from the traditional knowledge, so that students can learn and understand more quickly, specifically and profoundly, and be able to fully apply the learned music expertise.

Music itself is a communication of mind, which is connected with many aesthetic feelings, emotional and psychological experiences and aesthetic consciousness activities. Orff's music is precisely the pursuit of the exchange of music and heart, especially in the education of music in which students can take the initiative to achieve this communication from their own heart. It emphasizes the importance of music education in its own development. According to Orff's original principle of sexual music education, students' perception and reaction ability, comprehension ability, coordination ability of various parts of the body or mind and brain, memory, creativity, communication and communication skills are cultivated, and at the same time, students' artistic accomplishments are cultivated: The ability to feel (and affective experience), performance, and creation, and to explore, discover, express, and create art through personally engaged activities (say, sing, play, move, listen, play, etc.).

The contribution of Orff's education system is that he puts forward a way to enable students to enter the music learning naturally and smoothly, and to develop their imagination, creativity and all aspects of ability by allowing students to participate in music activities, so that students can share and share a comprehensive and complete musical aesthetic experience. It opens a new path for students to develop their individuality and sociality. Orff's educational idea, which in his own words, is, "music should be an important part of school education as other subjects, because music can cultivate the students' emotions, imagination and personality." He also said many times: "this system is not just the form of music, but also is the integration of actions, language and music. Students are not passive listeners, but active participants in music creation. It is simple and easy, and has no redundant structure. It is close to the nature of life, nature and students. It is a good mentor and friend for

students. From this we can see that in music education, music is only a means of education, and education is the purpose of talents.

\section{THE STATUS QUO OF MUSIC TEACHING IN CHINA}

The basic philosophy of Orff's music teaching method is to appeal to sensibility and return to humanity, that is, to proceed from the nature and origin of music production. Emphasis is placed on expressing people's emotions and feelings through music, language, and dance, inspiring people's 
emotional expression instincts, and achieving people's emotional resonance. In Orff's music teaching method, the primary task is to continuously stimulate people's instinctive behavior so that people can express themselves through various musical forms when they have the desire to express their emotions. It is not necessary to achieve a specific goal through music teaching. It is not that the students should achieve a good and high level of performance. Instead, students should be able to speak freely in music and be able to express themselves through music, thereby stimulating their individual development and development of creativity and personality.

The current music teaching method in China does not emphasize emotional stimulation and emotional resonance, but teaches knowledge of music theory, musical skills and abilities, and wants to achieve the goal of aesthetic education. Traditional music teaching methods have the following characteristics: singleness, boring, skill, nationality, and authority, which is completely contrary to the philosophy of the Orff music teaching method. Therefore, to make full use of Orff's music teaching method, the current music teaching should first change the teaching purpose, that is, music teaching no longer intends to achieve a certain purpose. Instead, it is necessary to cultivate students' musical personality and creativity, inspire students' emotions through music, and ultimately achieve emotional resonance. American educators often emphasize China's education issues and emphasize that Chinese education is very rigorous. It has strict logic and rich knowledge. Students who are trained in this way have a strong ability in abstract thinking, so they will achieve great prizes in the Olympic Science Competition. However, this type of education has poor performance capacity. The so-called behavioral ability is the ability to create, professionalism, and interpersonal skills. Therefore, the current situation caused by our education system is that the higher the education, the worse the right brain. Orff's music education is to exercise the right brain operation, which is conducive to man's ability to operate, which is just a major deficiency to make up for China's education.

\section{THE COMBINATION OF ORFF'S MUSIC TEACHING METHOD AND CHINESE MUSIC TEACHING THEORY}

Prerequisites. The prerequisite for a correct combination of Orff's music teaching method with our country's existing music teaching is that our country's music education scholars must profoundly understand the philosophy and philosophy of Orff's music teaching method. Orff's music teaching method originated from Orff's dissatisfaction with the music creation at the time. Therefore, under the influence and inspiration of modern dance, Orff produced the idea of combining dance and music. Later, this idea evolved an educational philosophy that combines music with percussion. The three important principles of Orff's music teaching method are: starting from students (the primary principle of Orff's music teaching method); emphasizing that music learners must actively learn music through personal practice; cultivate music learners' self-creativity. These three important principles emphasize to a large extent the student-centered approach. They cannot mechanically instill knowledge of textbooks and music and knowledge in students. They cannot simply teach students how to sing songs and ignore students' musical experiences and musical experiences.

Influences. Since the early $80 \mathrm{~s}$, the music education system of Karl Orff school has been introduced into China. It has become a kind of foreign music education system which is widely accepted and influential in the history of contemporary music education in China. It has been innovating and developing in China, and has constantly creation of new experiences and new forms with Chinese characteristics and own national cultural characteristics, which make us quickly integrate with the development of world music education at the beginning of the reform of music education. It has a high starting point and rapid development, which has played a great role in promoting the reform of music education in China. Orff's music entered China, breaking the backward teaching appearance of teachers and students in Chinese traditional music education, with a comprehensive and open musical field of vision, let the students in the environment full of music atmosphere, enjoy music, feel music, enjoy music, study music and create music. Therefore, the deep 
purpose of Orff's music teaching method is not to train students to become musicians, but to cultivate a healthy person.

The combination of Orff's music teaching method and Chinese music teaching practice. In the philosophy of Orff's music teaching method, students sing and dance are all derived from their own musical instincts, which are in accordance with the nature of human nature. Therefore, for students, singing, playing and dancing are not too difficult, and some of the talented students can reach a certain level. In this natural situation, students have no mental burden, and they can not only achieve their own satisfaction, but also can release their nature, stimulate their feelings, and achieve the emotional resonance between people and music, and between people and people. At the same time, it can stimulate the creativity of the students and cultivate the healthy personality of the students.

China's music teaching method has a certain degree of imitative and skill-oriented tendencies, and music teaching has also adopted a solid teaching idea, which has played a great hindrance in the cultivation of Chinese students' creativity.

In the past when using western music teaching methods, Chinese teachers did not notice the cultural differences. However, the cultural differences between China and the West are also reflected in music education. For example, China is good at expressing rich and profound thoughts with very few words, while the West is good at expressing logical thinking and expressing completeness and clarity. China attaches more importance to the integrity of things, while the West pays more attention to individual development and separation of subject and object. Therefore, this requires that Chinese teachers should not use Western Orff music teaching methods blindly, without fully recognize the complementarities between Orff's music teaching method and China music education.

\section{APPLICATION OF ORFF'S MUSIC TEACHING METHOD IN CHINA}

Rhythm training. Orff believes that rhythm in music is more fundamental than melody. Rhythm can exist without melody, while melody could not. Rhythm is the life and power of music and link language, dance and music together. Orff trains students's sense of rhythm from two aspects: language rhythm and movement rhythm. First, let the students extract simple rhythmic units from submission, nursery rhymes, poetry and the names of their familiar things. The minimum size of these "units" can be repeated in two sections. In this way, the students are trained to be accurate in hearing, agility, memory, and rhythm. Another form of rhythm training is "momentum" activity. The implementation of "momentum" activities should consider students's learning ability of different ages. The difficulty of "momentum" activities is reflected in rhythm, movement, voice and texture complexity, and the size of work structure.

Instrumental ensemble. Orff instruments are mainly percussion instruments that are operated by large muscles and are tools for music education. Teachers can make full use of their own national instruments. Such as tambourine, snare drums, drums, wooden fish, double barrels, terracotta plates, clay pots, oysters, bawu, cucurbits, mouth organ, etc. And can also use objects that can be heard in life, such as stones, floors, cups, plates, bottles, etc.

Language, action, dance and music teaching. Orff has designed a set of musical instruments with accurate timbre, beautiful timbre, fixed pitch, and percussion instruments with no fixed pitch and a rhythm and tone effect, as well as a flute, timpani and so on. The note instruments are xylophone, carillon, and steel sheet and so on. According to its range, they are divided into bass xylophone, alto xylophone, treble xylophone, alto glockenspiel, treble glockenspiel, mid-range steel sheet, and treble steel sheet. The sound bar is placed on a resonant box with a volume reinforcement function, and it can be removed and placed at will. A percussion instrument without a fixed pitch, such as triangle, bells, cymbals, castanets, maracas, drum etc.. Because these instruments (except clarinet), all adopt the way of striking, no fingering difficulties, and no technical burden, so it is easy for students to operate. At the same time, they are also the most easy to highlight the characteristics of rhythm, conducive to the training of rhythm, beautiful tone color rich in color, can arouse students's imagination, therefore, improve students's interest in learning, and have achieved good teaching 
results. The teaching of Orff system often adopts multi voice structure. For example, in the preceding rhythm part, it has been summarized that the momentum is often the rhythm of multi voice. In the arrangement of multiple voices, a fixed or constant repetition of the same tone is often used to accompany songs, music and recitation, or to perform ensembles and ensembles. These multi-voice structures are structured, simple, easy to remember, easy to play, and easy to improvise. In Orff's textbook, there are lots of works that Orff compiled for this instrument, which has high artistic value of German folk songs and nursery rhymes. Creativity is one of the most important characteristics of Orff's teaching method.

Improvisational music ability training. Improvisational music is the oldest and most natural form of musical activity and the most direct form of emotional expression. Improvisation of music activities can be developed from guiding students to experience a short period of motivation, questions and answers, and phrases to complete works of different structures. In the process of improvisation, students will gain a sense of accomplishment and satisfaction. This is an important means of stimulating students' interest in learning and potential creativity. At the same time, improvisation is also the main means of exploring the form of music organization.

The organic combination and penetration of music theory knowledge. The mastery of music theory is very important. It is the basic condition for studying other professional courses. Without master of the knowledge of music theory, other professional skills courses cannot even be performed. We should appropriately integrate the knowledge of music theory in the Orff lesson according to the situation. Such as the understanding of white keys and black keys and the understanding of the nature of the intervals: Let tall students act as adults to do self-keys, short and short students as students do black keys, and two adults add one child as second and two adults. There are no students in the middle and so on, so that the students can use the game to understand natural intervals.

\section{OBSTACLES AND SOLUTIONS TO THE IMPLEMENTATION OF ORFF'S MUSIC TEACHING METHOD IN CHINESE MUSIC EDUCATION}

Implementation obstacles. The thinking patterns and aesthetic standards of Chinese people are greatly different from Western ideas. The Chinese students have passively accepted the indoctrination from teachers and parents since childhood. Their own ideas cannot be expressed directly, but will be expressed in a subtle way, which, to a large extent, has caused obstacles in Orff's music teaching method to be implemented in Chinese music education. In Orff's music teaching method, students are required to fully release their emotions, to exert their subjective initiative, and to be able to display their individuality and creativity in the classroom. In Orff's music teaching method, Orff advocates "improvisation" teaching, and this "improvisation" teaching. However, this kind of "improvisation" teaching is to a large extent contrary to our traditional "steadiness" principle. The interactive state in the improvisational teaching method is the most direct instinctive emotional response of people, and it is the most authentic emotional interaction and emotional resonance of people. Today's education in China has not met the requirements of Orff's music teaching method.

Solutions \& countermeasures. First of all, it is necessary for Chinese music educators to have serious and rigorous teaching spirit. When students are unable to let go of their emotional feelings, they need teachers to give full play to their ability to mobilize and stimulate their instinctive emotions, so that students can use their own body language or rhythm while they taste music. In order to achieve the emotional interaction and emotional resonance between students, students and music, the students really meet the requirements of the Orff music teaching method. Furthermore, our country's music education model and talent training model place too much emphasis on teacher education. There is no interaction between students and teachers. The model of class is simply a single path for teachers to talk and students to listen, so there is no interactive teaching. The model not only violates the teaching principles of Orff's music teaching method, but also has a great impediment to the development of China's music education. While the teacher fully mobilizes students, students are required to give full play to their subjective initiative, express their feelings in a more straightforward manner, and express their emotions through singing, singing and dancing. This reflects the essence of Orff's music 
teaching method to a great extent, and demonstrates the people-oriented principle of Orff's music teaching method. Following is some detailed cases.

Classroom situation setting. A good classroom situation is the physical environment of music teaching. It can arouse students' interest in learning. Students are affected by the emotions in their learning. They have a positive attitude toward learning and can improve the quality of learning. For example, the classroom layout of kindergartens is colorful and colorful, giving people a feeling of liveliness. The paste of various small animals sticks to the wall to attract students's attention, so that they have an aesthetic taste. The choice of classroom in primary school music lessons has certain limitations. At present, most of the primary school music class in our country is still in the original classroom of culture class. It will inevitably lead to the situation that the number is more and the action is not open. In this case, the teachers and students are easy to produce a sense of distance, which is not conducive to the free play of the students, and the free creation of various movements.

Situation import. Teachers should add some body movements to guide students, help students to deepen their impression of new things, improve learning efficiency and interest in learning. Orff's teaching system emphasizes the combination of music and movement, dance, and language. It fosters students's creative abilities and enables students to enter music imaginarily. However, many primary school music lessons in China are not like this. Teachers can use appropriate body movements to guide students and lead students to experience the characteristics of beats, which not only enables students to accurately capture the rhythm of the rhythm, but also can activate the atmosphere of the classroom, and stimulate the students' interest in learning, enable students to imagine to enter the music, and foster the creativity of the students.

Learning interest. Teaching methods are very important. Some teachers use Orff instruments, which can not only help students to participate in music activities, but also stimulate their interest. Such as triangle, touch the bell, bell. Orff's teaching method points out that every child is willing to participate in the practice of music. In the process of participating in music practice activities, we should pay attention to details. For example, in the music class in the culture class classroom, the teacher sends the musical instruments to the students who are actively involved in the music practice. Some of the students who get the musical instruments are sitting in the back, so when the music activities carried out, and the students who are sitting in the front row and do not get the instruments have to look back, some students even didnt take part in the music practice, the case is a problem of detail. At this time, the teacher should call the students of the instrument to the front to show them, so that the students below can not look back passively, so that they don't have to change the posture, directly look forward, and interact with each other through this interaction. Way can ensure that every student can participate in music practice activities, so that each student can get experience and improve classroom teaching efficiency.

\section{THE APPLICATION OF ORFF'S MUSIC TEACHING METHOD AND THE RESEARCH IDEAS IN MUSIC CLASS}

Orff music teaching method can comprehensively cultivate the students' music quality, so Orff music teaching concept is penetrated into the teaching of various music departments, grasps the basic core of Orff's music teaching idea, and expands the application of Orff music teaching method in the teaching of various subjects.

Guide students to actively integrate into the music classroom. In the course of guiding students to participate in the music practice actively, the premise is to require teachers to change the teaching method in time according to the psychological age characteristics of the students. The new curriculum concept indicates that the whole process of teaching is the combination of teachers' teaching and students' learning closely. The whole teaching process is the result of interaction between teachers and students, and is the product of common development. Taking the students as the basis, we must first understand the psychological age characteristics of the professor at this time. Only by grasping the psychological characteristics of the object can we carry out the appropriate teaching methods so as to achieve the teaching goal. Then, for the students in the lower grade, their 
cognitive and psychological characteristics are in the teaching link, they are full of curiosity about the fresh things, are more active on the limbs, and are good at imitating the behavior made by the teachers and students, and the students' thinking has a certain direct, concrete and image character. They like teachers to use their favorite teaching methods. If teachers can grasp the psychological age characteristics of the students in time and adopt the teaching methods that attract them, they can make them interested in learning music, and also facilitate the teachers to create a lively, happy and relaxed atmosphere of teaching, in order to promote the development of the students.

Scenario creation guidance. Situational creation of this teaching method is a mutually beneficial teaching model for teachers and students. Teachers are required to follow the teaching content and teaching requirements, and also to combine the actual level of students, to create specific teaching situations and classroom environment atmosphere for students, so that students can be emotionally infected through imagination and obtain emotional experience. Resonates in emotions and integrates into the situation created by the teacher. To achieve the purpose of stimulating students' interest in music learning, and to enrich students' imaginations, so that they can generate the motivation to actively study music, enable students to actively participate in the music activities organized by teachers, and feel the charm of music together. In the teaching of music classrooms, according to different teaching contents, students' mental age characteristics, and the use of creative situation guidance, students can be motivated to learn music and make them deepen their impressions in the context, through their own imagination. Feeling, obtaining emotional experience, perceiving and understanding new things in the context, but also conducive to the teacher's next lecture, improve the teaching efficiency of primary school music classroom teaching.

The application of Orff music teaching method in vocal music course. First of all, breathing and arpeggio training are performed in a game-like manner. Choose to imitate animal calls, use intuitive methods to enter abstract sound training, etc. Second step is expressing vocal works with simple singing.

The application of Orff music teaching method in the course of music theory and solfeggio. Training rhythm from pronouns to train students' perception of rhythm and expressiveness in rhythm operation, for example, quarter notes use "walk", eighth notes use "running", etc. In the outstanding performance in listening training, listening training is at the core of music education and it is of great significance. Through students' personal involvement, they reacted improvisingly to listening through means such as action, music, and painting, and cultivated students' listening ability, auditory memory, and comprehension ability.

The application of Orff teaching method in dance course. In view of the characteristics of the students' zero base in preschool education, in the basic training of the dance, we can use the modules of rhythm change, azimuth conversion, and test singing to visualize and imitate the form, dynamics and posture of various creatures, and use the vocabulary of dance to show the lively and graceful dance and basic training.

The application of Orff teaching method in music appreciation course. Putting music in the form of storytelling or body rhythm allows students to enter the world of music, to experience the joys and sorrows of music, to meditation and frustration, and to cultivate the heart and perfect personality.

The application of Orff teaching method in piano course. To break the traditional mode of simple playing, the course of the keyboard is divided into three stages, that is, the piano foundation, the improvisational accompaniment, the self playing and singing, and then the students of the pre-school education in higher vocational education can be qualified for the teaching of the music class in the kindergarten.

In the classroom teaching practice, adding interesting music, applying the ensemble, the round play, the solo, the relay, the group and so on, strengthens the group effect of the collective class, changes the past boring practice, and gives the students to observe and discuss each other in the teaching process, and guide the students to learn effectively. 


\section{THE APPLICATION CASE OF ORFF'S MUSIC TEACHING METHOD}

Orff music teaching method is dominated by "improvisation" teaching, which is, allowing students to fully own the right to inspire their own emotions in music teaching, to achieve a profound experience of music. The specific performance in teaching is to let students choose their own favorite instruments or choose to sing and dance to express their emotions and ideas.

A well-known music educator in China, Li Tanna, used the Orff music teaching method correctly when he taught the students "League-faced ambush." Before class, Mr. Li sent a cardboard box to each student to allow students to create different voices through paper boxes and encourage students to continue to encourage them. The students were all new to the class method and were very willing to try it. In this good classroom atmosphere, students began to use their fingers to scratch or punch the cardboard boxes, and some of them beat the paper boxes with their hands while the students were able to enlighten each other, find out a lot of different sounds, and paper boxes made a lot of different tone.

Afterwards, Li used a method that was different from the classmates and conducted heuristic education for the students. This is the original nature education in the "Orff's Music Teaching Method", which uses everything found in life to recreate it and use it as a teaching aid. Later, the teacher beat out several rhythm sets with paper boxes. The students were meticulously watching each movement of the teacher and did not want to miss any details. In this process, Ms. Li fully stimulated the subjectivity and initiative of students in their studies, allowing them to change from passive learning to active learning and fully reflecting the teaching methods of Orff student-centered basic teaching principles. Then, Mr. Li wrote the theme of this class "League-faced ambush" on the blackboard and let students think of this historical event. The students worked hard to supplement the blank memory and finally recalled this historical event quickly. Afterwards, Ms. Li put it on the "League-faced ambush" to allow students to associate each rhythm group in the tune with the one they had just learned. When the tune was put, the students were very quiet and listened concentrically for fear of missing any of the details. Then Teacher Li did not give a professional explanation to this piece, but instead discussed it with the students. During the discussion and exchange, the students gradually learned the music theory of the piece. Then Teacher Li wrote the structure of this song on the blackboard: The camp - the expedition - the ambush in ten sides (small battles, big battles) - the song of $\mathrm{Chu}$ - won the camp.

In the final teaching session, Teacher Li divided the students into groups and asked them to show the "League-faced ambush" by means of the fight against paper boxes. The students were all very team-conscious, so under this kind of competitive cooperation, Students have exerted their intelligence and creativity, and strive to make their own contribution to the team they belong to. On this basis, they have improved the team spirit of the students. When students were frustrated with their achievements, Professor Li gave timely encouragement and asked the other team's students to give an encouraging assessment to the team. Teacher Li understood the essence of Orff's music teaching method profoundly and applied it to the actual teaching. In classroom teaching, students' initiative and autonomy were fully exerted, students' motivation and passion for learning were stimulated, and students' emotional interaction and emotional resonance were well aroused.

\section{SUMMARY}

From ancient times to the present, China ancient civilization always meets such difficulties and obstacles when accepting a new idea. But as long as this new concept is beneficial to the development of our country, we should work hard to make it take root and grow up in the right soil. Since the Orff music teaching method has been proven its correctness, and it is accepted and recognized by most countries in the world. What we need to do is to face up to the existing problems in our country's music education and correct these problems according to the authoritative Orff music teaching method, and on the basis of correcting the correct theory of Orff music teaching method, so as to improve the quality of Chinese music teaching in an all-round way. In view of the problems existing in the current music class in China, this paper focuses on the teaching thought of Orff, analyzes the 
advanced teaching cases, and puts forward four suggestions. It is believed that in the course of music classroom teaching, we should guide the students' personal practice and actively integrate into the music class, develop the students' personality and improve the students' enthusiasm for learning. In the course of teaching, the students' creative thinking is cultivated and the four aspects of the proper application of multimedia teaching are analyzed and explained. In order to seize the attention of the children, improve their interest in music learning, and what kind of teaching methods should be used as teachers to improve the efficiency of classroom teaching in Chinese music lessons in time according to the psychological age characteristics of the pupils.

Through the analysis and study of the teaching lesson cases, and drawing on excellent methods, and citing music teaching, the integration of Orff's teaching ideas with music lessons, is not only teaching the method of playing musical instruments and singing, but also music activities that can mobilize students' interests so that they are willing to participate in the way of learning together. Allowing students to improve the quality of students' music in music practice activities, inspire students' interest in learning, develop students' thinking ability, and cultivate cooperation spirit, which will help students develop the overall quality of their students.

\section{REFERENCES}

[1] David Isharot. Focus on music practice - philosophy of new music education, [M]. Shanghai: Shanghai Music Publishing House, 2009: 55.

[2] Li Tina, Xiu Hailin, Yin Aiqing. Orff's music education principles and practice [M]. Shanghai: Shanghai Music Publishing House, 2002: 48.

[3] Fang Shaomeng. The Inspiration of Orff's music teaching to students's bilingual teaching [J]. Students Development Study, 2011.03: 120-122.

[4] Liao Hongying. Discussion on Orff's music teaching reform[J]. Market Forum, 2008.08: 150-152.

[5] Wu Xiaoling. New Curriculum Reform: The Turning Point of the Localization of Educational Theory [J]. Education Theory and Practice, 2002, 22(11):35-38

[6] Zhu Yujiang. On The Shift of Focus of Contemporary Music Education[J]. Journal of Nantong University (Education Science Edition), 2005(3): 90

[7] Li Tina, Xiu Hailin, Yin Aiqing. Orff's Music Education Principles and Practice [M]. Shanghai Music Publishing House, 2002: 48

[8] David Elliot. Concerned about Music Practice - The Philosophy of New Music Education[M]: Xie Jiaxing and other translations. Shanghai Music Publishing House, 2009.55 